\title{
Prevalence and Predictors of Depression among Diabetes Mellitus in Adult Population
}

P Dahal*, G Balamurugan and AU Basavaraja

Ramaiah Institute of Nursing Education and Research, Bangalore, Karnataka, India

\begin{abstract}
Introduction: Diabetes mellitus and depression are chronic debilitating conditions that are associated with high rates of complications and death. People with diabetes who have depression often find it more difficult to follow diabetes treatment recommendation, had increased healthcare costs, and poor lower quality of life. This study was conducted to determine the prevalence and determinants of depression among diabetes mellitus patients.
\end{abstract}

Methods: This was a descriptive cross-sectional study done in 100 diabetes mellitus patients in Rajmahal Villas Hospital, Bangalore, India. Nonprobability convenient sampling technique was used. Depression was assessed by using Major Depression Inventory. The collected data were analysed by using descriptive and inferential statistics.

Results: Of 100 patients with diabetes mellitus, $91 \%$ of the enrolled patients were above 40 years old. The study findings showed that the prevalence of depression among diabetes mellitus patient was $9 \%$. Among enrolled patients, $23 \%$ had other health problems and $49 \%$ didn't exercise daily. The depression in diabetes mellitus was significantly more common in those patients who had other health problems $(\mathrm{P}=0.02)$ and didn't exercise regularly $(\mathrm{P}=0.03)$.

Discussion: Among diabetes mellitus, depression is common co-morbidity. The presence of other health problems and sedentary lifestyle predict the depression among diabetes mellitus patients.

Keywords: Depression; Type 2 diabetes mellitus; Prevalence; Predictor

\section{Introduction}

One of the greatest challenges of medicine in the $21^{\text {st }}$ century is comorbidity, where two or more disease occurs together in the same individual [1]. Diabetes mellitus is a chronic disease which affects virtually every organ in the human system. The World Health Organization projected that 300 million people will suffer from diabetes by 2025 [2]. It is also believed that by 2025 , more than $75 \%$ of the world population with diabetes mellitus will reside in developing countries and the countries with the largest population of adults with diabetes will include: India, China, and the United States [3]. Diabetes is fast gaining the status of a potential epidemic in India with more than 62 million diabetic individuals currently diagnosed with the disease [4]. Diabetes caused 5.1 million deaths in 2013. Every six seconds a person dies from diabetes [5].

Diabetes and depression are chronic debilitating conditions that are associated with high rates of complications and death. People with diabetes who have depression often find it more difficult to follow diabetes treatment recommendations and have poor metabolic control. They have also higher complication rates, increased health care use, and increased disability, lost productivity, lower quality of life and increased risk of death [6]. Biologists and epidemiologists identify depression as both a cause and consequence of diabetes. While medical social scientists have elucidated some of the complex socioeconomic and psychophysiological pathways linking the two chronic conditions [7]. Diabetes mellitus is associated with doubled risk for comorbid depression compared to healthy controls, hampering the patient's quality of life [8].

Most of the time, depression is not considered an important factor, often ignored and left untreated [9]. To muddle through the everyday tribulations involved in supervision and handling of disease is barely challenging for patients but parallel for caretakers and healthcare professionals [10]. Therefore, based on the review of Literature researcher identified that depression is contributing factor to mortality, morbidity and increase health care costs and many times physicians are unable to identify depression in patients with Type 2 Diabetes Mellitus. So for the integrated management of comorbidity of depression with Type 2 Diabetes mellitus, it is necessary to carry out this study. This study is author's endeavor to find out the prevalence of depression and its determinants among diabetes mellitus patients.

\section{Methods}

\section{Study design}

We conducted a descriptive cross-sectional study in Department of Internal Medicine, Rajmahal Villas Hospital, Bangalore in southern India after obtaining formal permission from the concerned authority. The data collection period was four weeks, from $26^{\text {th }}$ Nov to $21^{\text {st }}$ Dec 2015. Patient of Type 2 Diabetes Mellitus of age 18 years or older visiting the Outpatient Department were enrolled in this study after taking written informed consent. Those participants who were already diagnosed psychiatric problems were excluded from the study. The primary objective of the study was to find the prevalence of depression among patients with Type 2 Diabetes Mellitus and to find the association between depression and socio-demographic variables.

*Corresponding author: P Dahal, Ramaiah Institute of Nursing Education and Research, Bangalore, Karnataka 560054, India, Tel: +977 9842560455; E-mail: piyushdahal00@gmail.com

Received: September 16, 2017; Accepted: October 13, 2017; Published: October 20, 2017

Citation: Dahal P, Balamurugan G, Basavaraja AU (2017) Prevalence and Predictors of Depression among Diabetes Mellitus in Adult Population. J Psychiatry 20: 430. doi:10.4172/2378-5756.1000430

Copyright: $\odot 2017$ Dahal P, et al. This is an open-access article distributed under the terms of the Creative Commons Attribution License, which permits unrestricted use, distribution, and reproduction in any medium, provided the original author and source are credited 
Citation: Dahal P, Balamurugan G, Basavaraja AU (2017) Prevalence and Predictors of Depression among Diabetes Mellitus in Adult Population. J Psychiatry 20: 430. doi:10.4172/2378-5756.1000430

Page 2 of 3

\section{Data collection procedure}

Patients were given preformed proforma to fill the data regarding socio-demographic profile and status of diabetes mellitus. Major depression inventory tool was used to assess depression. The duration of the interview was 10 -minutes and taken in a single sitting.

\section{Statistical analysis}

All the data were entered in Ms-Excel 2010 and analyzed by using SPSS VERSION 21.0. For descriptive analysis, frequency, percentage, mean, median and standard deviation were used whereas, for inferential statistics Chi-square test was used. All data were presented in tabular form. Data were considered as significant at a confidence interval of $95 \%$ if the $\mathrm{P}$ value is $<0.05$

\section{Result}

From $26^{\text {th }}$ Nov 2015 to $21^{\text {st }}$ Dec 2015 , a total of 100 patients diagnosed with Type 2 DM were selected by using non-probability convenient sampling technique. Questionnaire on socio-demographic profile and Modified Major Depression Inventory was administered to the subjects under study. Baseline characteristics of study participants $(\mathrm{n}=100)$ (Table 1).

Table 1 show that majority of the study population represents the age group of $40-49$ years. Similarly, $68 \%$ of the study population belongs to the male and 26-30 category of body mass index each. Likewise, majority i.e., $65 \%$ falls under $0-90$ category of the duration of diabetes and 51\% carry out daily exercise. Moreover, most of the study participants take oral medications and living in a nuclear family. Most of the participants i.e., $85 \%$ had family income $\leq 1,00,000$ and $77 \%$ had no other health problems.

Demonstrate that there was a statistically significant association between depression and associated health problem $(\mathrm{P}=0.002)$. Similarly, the association between exercise and depression was significant $(\mathrm{P}=0.003)$ (Table 2).

\begin{tabular}{|c|c|c|}
\hline Characteristics & Category & Frequency \\
\hline \multirow{4}{*}{ Age (years) } & $30-39$ & 9 \\
\hline & $40-49$ & 38 \\
\hline & $50-59$ & 29 \\
\hline & $\geq 60$ & 24 \\
\hline \multirow{2}{*}{ Gender } & Male & 68 \\
\hline & Female & 32 \\
\hline \multirow{2}{*}{ Body Mass Index $\left(\mathrm{kg} / \mathrm{m}^{2}\right)$} & $19-25$ & 30 \\
\hline & $>25$ & 70 \\
\hline \multirow{4}{*}{ Duration of diabetes in months } & $0-90$ & 65 \\
\hline & $91-180$ & 18 \\
\hline & $181-270$ & 11 \\
\hline & $271-360$ & 6 \\
\hline \multirow{2}{*}{ Daily Exercise } & Yes & 51 \\
\hline & No & 49 \\
\hline \multirow{2}{*}{ Family Type } & Nuclear & 69 \\
\hline & Joint & 31 \\
\hline \multirow{2}{*}{ Family Income in IRS } & $\leq 1,00,000$ & 85 \\
\hline & $>1,00,000$ & 15 \\
\hline \multirow{2}{*}{ Other Health Problems } & Yes & 23 \\
\hline & No & 77 \\
\hline Depression among study population & & \\
\hline
\end{tabular}

Table 1: Baseline characteristics of study population $(n=100)$.

\begin{tabular}{|c|c|c|c|c|}
\hline \multirow[b]{2}{*}{ Characteristics } & \multirow[b]{2}{*}{ Category } & \multicolumn{2}{|c|}{ Level of depression } & \multirow[b]{2}{*}{$P$ value } \\
\hline & & $\begin{array}{c}\text { Below } \\
\text { median }\end{array}$ & Above median & \\
\hline \multirow{2}{*}{ Duration of diabetes } & $\leq 72$ months & 30 & 23 & \multirow{2}{*}{0.169} \\
\hline & $>72$ months & 20 & 27 & \\
\hline \multirow{2}{*}{ Body Mass Index } & $\leq 26 \mathrm{mg} / \mathrm{kg}^{2}$ & 28 & 23 & \multirow{2}{*}{0.317} \\
\hline & $>26 \mathrm{mg} / \mathrm{kg}^{2}$ & 22 & 27 & \\
\hline \multirow{2}{*}{ Family Type } & Nuclear & 39 & 30 & \multirow{2}{*}{0.052} \\
\hline & Joint & 11 & 20 & \\
\hline \multirow{2}{*}{ Family Income } & $\leq$ Rs. 60,000 & 33 & 24 & \multirow{2}{*}{0.069} \\
\hline & $>$ Rs. 60,000 & 17 & 26 & \\
\hline \multirow{2}{*}{ Health Problem } & Absence & 45 & 32 & \multirow{2}{*}{0.002} \\
\hline & Presence & 5 & 18 & \\
\hline \multirow{2}{*}{ Exercise } & Yes & 33 & 18 & \multirow{2}{*}{0.003} \\
\hline & No & 17 & 32 & \\
\hline
\end{tabular}

Table 2: Association between depression and socio-demographic variables.

\section{Discussion}

Of 100 diabetes mellitus, the prevalence of depression in the present study was $9 \%$. In a study conducted by Thomas J et al. the prevalence of depression was reported up to $36 \%$ among type 2 Diabetes Mellitus. The probable factors for low prevalence of depression in our study population were exercise and low rate of associated health problems in the study population. Bebbington P et al. reported that male gender is protective factors against depression [11]. The predominance of the male population (68\%) in our study might have contributed to the low prevalence of depression among diabetes mellitus patients in our study.

Among the total study population, the occurrence of depression was significantly low who does the exercise. This finding corroborates with the study of Guszkowska $M$ et al. who reported that aerobic exercise including jogging, cycling, swimming, and dancing reduces depression [12]. This protective effect of exercise on depression was proposed to be mediated by enhanced blood circulation to a hypothalamicpituitary-adrenal axis which elevates the mood. Other beneficial effects of exercise encompass the social interaction, increased motivation, distraction from stress and increased confidence $[12,13]$.

Diabetes mellitus is a chronic disease that is frequently associated with other health problems like hypertension $(60.2 \%)$ [14], hypothyroidism (13\%) etc. [15]. These associations with other health problems complicate the natural course of the disease and add extra burden among patients with diabetes mellitus. In this study too, Depression was significantly higher among those patient of diabetes mellitus who has associated other health problems than diabetes mellitus alone $(\mathrm{P}=0.02)$. The depression among hypertensive and hypothyroid patients were $26.8 \%$ [16] and $13 \%$ [17] respectively. These all data corroborate our finding that depression is significantly more with diabetes with other health problems. Hence physician while caring diabetes mellitus should give extra attention to screen depression to them who have other health problems.

Even though the prior evidence showed concordance in the prevalence of depression and increasing body mass index, in this study population, body mass index variation was not associated with depression. This contrast in finding might be due to an enrollment of few numbers of patients with normal body mass index in this study. Duration of diabetes mellitus, family income, and family type had no significant association with diabetes mellitus in the study population.

\section{Limitation}

The study was a single-centered study with limited sample size. 
Citation: Dahal P, Balamurugan G, Basavaraja AU (2017) Prevalence and Predictors of Depression among Diabetes Mellitus in Adult Population. J Psychiatry 20: 430. doi:10.4172/2378-5756.1000430

Page 3 of 3

\section{Conclusion}

Among diabetes mellitus, depression is common co-morbidity. The presence of other health problems and sedentary lifestyle predict the depression among diabetes mellitus patients.

\section{Future Direction}

This study highlights the need for further research to find out the prevalence of depression and its impact on management among diabetes mellitus patient in larger sample size.

\section{Conflict of Interest}

The author declares conflict of interest to none.

\section{Acknowledgement}

The authors acknowledge for consistent support from the management of Ramaiah Institute of Nursing Education and Research and Raj Mahal Villas Hospital.

\section{References}

1. Graham CC, Sartorius N, Cimino LCGL (2014) Diabetes and depression in general practice: meeting the challenges of managing comorbidity. $\mathrm{Br} \mathrm{J}$ Gen Pract 64: 386-387.

2. Raval A, Dhanaraj E, Bhansali A, Tiwari $P$ (2010) Prevalence \& determinants of depression in type 2 diabetes patients in a tertiary care centre. Indian $\mathrm{J} \mathrm{Med}$ Res 132: 195-200.

3. Egede LE, Ellis C (2010) Diabetes and depression: Global perspectives. Diabetes Res Clin Pract 87: 302-312.

4. Kumar A, Goel MK, Jain RB, Khanna V (2013) India towards diabetes control: Key issues. Australas Med J 6: 524-531.

5. Aguiree F, Brown A, Cho N, Dahlquist G (2013) IDF Diabetes Atlas.
6. Kaveeshwar SAJC (2014) The current state of diabetes mellitus in India Australas Med J 7: 45-48.

7. Mendenhall E, Weaver LJ (2014) Reorienting women's health in low- and middle-income countries: The case of depression and Type 2 diabetes. Glob Health Action 7: 1-4.

8. Pouwer F (2010) Does emotional stress cause type 2 diabetes mellitus? A review from the European Depression in Diabetes (EDID) Research Consortium. Discov Med 45: 112-118.

9. Abbas A, Nasir H, Zehra A, Noor A, Jabbar FA, et al. (2015) Assessment of depression as comorbidity in diabetes mellitus patients using Beck Depression Inventory II (BDI II) scale. J Young Pharm 7: 206-216.

10. Javed S, Maqsood A (2015) Diabetes associated distress: Implications for coping and treatment. Appl Psychol 12: 1-19.

11. Bebbington $P$ (1996) The origins of sex differences in depressive disorder: Bridging the gap. Int Rev Psychiatry 8: 295-332.

12. Guszkowska M (2004) Effects of exercise on anxiety, depression and mood. Psychiatr Pol 38: 611-620.

13. Peluso MA (2005) Physical activity and mental health: The association between exercise and mood. Clinics 60: 61-70.

14. Kabakov E, Norymberg C, Osher E, Koffler M, Tordjman K, et al. (2006) Prevalence of hypertension in type 2 diabetes mellitus: impact of the tightening definition of high blood pressure and association with confounding risk factors. J Cardiometab Syndr 1: 95-101.

15. Riley WJ, Maclaren NK, Lezotte DC, Spillar RP, Rosenbloom AL (1981) Thyroid autoimmunity in insulin-dependent diabetes mellitus: The case for routine screening. J Pediatr 99: 350-354.

16. Li Z, Li Y, Chen L, Chen P, Hu Y (2015) Prevalence of depression in patients with hypertension. Medicine (Baltimore) 94: e1317.

17. Demartini B, Masu A, Scarone S, Pontiroli AE, Gambini O (2010) Prevalence of depression in patients affected by subclinical hypothyroidism. Panminerva Med 52: 277-282. 